\title{
Blockade of CC Chemokine Receptor 5 (CCR5)-Tropic Human Immunodeficiency Virus-1 Replication in Human Lymphoid Tissue by CC Chemokines
}

\author{
Leonid B. Margolis, Svetlana Glushakova, Jean-Charles Grivel, and Philip M. Murphy* \\ Laboratory of Molecular and Cellular Biophysics, National Institute of Child Health and Human Development, and *Laboratory of Host \\ Defenses, National Institute of Allergy and Infectious Diseases, National Institutes of Health, Bethesda, Maryland 20892
}

\begin{abstract}
The CC chemokines MIP-1 $\alpha$, MIP-1 $\beta$, and RANTES suppress replication of certain HIV-1 strains in cultured PBMC and $\mathrm{T}$ cell lines by blocking interaction of gp120 with $\mathrm{CC}$ chemokine receptor 5 (CCR5). However, the same chemokines can enhance HIV-1 replication in cultured macrophages. The net effect of chemokines on HIV-1 infection in intact lymphoid tissue, the major reservoir of $\mathrm{HIV}-1$ in vivo, is unknown and unpredictable since the tissue contains both $\mathrm{T}$ lymphocytes and macrophages. Here we show that exogenous MIP-1 $\alpha$, MIP-1 $\beta$, and RANTES markedly suppressed replication of CCR5-tropic HIV-1 strains in blocks of human lymphoid tissue infected ex vivo. Moreover, endogenous MIP-1 $\alpha$, MIP-1 $\beta$, and RANTES were upregulated in tissues infected ex vivo with CXC chemokine receptor 4-tropic but not CCR5-tropic HIV-1. Such an upregulation may contribute to the virus phenotype shift in the course of HIV disease in vivo. (J. Clin. Invest. 1998. 101:1876-1880.) Key words: AIDS • HIV • chemokine • leukocyte • receptor
\end{abstract}

\section{Introduction}

HIV infection in vivo is typically transmitted with virus variants classified as nonsyncytium-inducing or macrophage (M)tropic (1). These viral variants infect PBMC and macrophages but not certain $\mathrm{CD}^{+} \mathrm{T}$ cell lines. Usually these viruses predominate in early stages of HIV disease. Development of AIDS is often associated with a shift to predominance of T cell line (T)-tropic/syncytium-inducing viruses $(2,3)$. These strains can infect $\mathrm{T}$ cell lines and PBMC but not macrophages. The molecular determinants of HIV-1 cytotropism include the sequence of the gp120 portion of the viral envelope glycoprotein and specific chemokine receptors on target cells, which together with CD4 mediate fusion of the viral envelope with the target cell membrane (4).

In vitro, M-tropic HIV-1 isolates use CC chemokine receptor $5(\mathrm{CCR} 5)^{1}$ as a coreceptor for viral entry, whereas T-tropic

Address correspondence to Leonid Margolis, National Institutes of Health (NIH), Building 10, Room 10D14, Bethesda, MD 20892. Phone: 301-594-2476; FAX: 301-480-0857; E-mail: margolis@helix.nih.gov; or Philip Murphy, (NIH), Building 10, Room 11N113, Bethesda, MD 20892. Phone: 301-496-2877; FAX: 301-402-4369; E-mail: pmm@nih.gov

Received for publication 15 October 1997 and accepted in revised form 1 March 1998.

1. Abbreviations used in this paper: CCR5, CC chemokine receptor 5; CXCR4, CXC chemokine receptor 4.

The Journal of Clinical Investigation

Volume 101, Number 9, May 1998, 1876-1880

http://www.jci.org strains use CXC chemokine receptor 4 (CXCR4) (5-8). An important role for CCR5 for HIV infection in vivo was recently proved by finding that humans homozygous for an inactive mutant CCR5 allele have greatly diminished risk of infection with HIV-1 (9-12). CCR5 is the natural receptor for three CC chemokines, MIP-1 $\alpha$, MIP-1 $\beta$, and RANTES (13-15). In vitro, these chemokines inhibit infection by various CCR5tropic HIV-1 strains of T cell lines transfected with CCR5, of cell lines expressing endogenous CCR5, and of PBMC (5, 7, 8, 16) by blocking interaction of the viral envelope glycoprotein gp120 with CCR5 on the cell surface $(8,17)$. This has suggested that the chemokines themselves or chemokine derivatives could be developed as therapeutic and/or prophylactic agents against HIV-1 infection. However, through an unknown mechanism, the same chemokines can enhance replication of the same strains of HIV-1 in macrophages (18). Moreover, the effect of CC chemokines on HIV infection in lymphoid tissue, the major site of replication in vivo (19-21), is completely unknown. Various cell types including lymphocytes and macrophages are present in lymphoid tissue and are engaged in a complex interaction within the tissue cytoarchitecture. Based on experiments with isolated cells of one particular subset, it is impossible to predict the net effect of CC chemokines on HIV-1 replication in organized tissue. Recently we have developed a new model for studying HIV infection in blocks of human lymphoid tissue (histocultures) which retain their cytoarchitecture and support HIV-1 replication without exogenous activators $(22,23)$. Here we report the effect of MIP- $1 \alpha$, MIP-1 $\beta$, and RANTES on HIV-1 infection in this system.

\section{Methods}

Human tonsils obtained from patients undergoing tonsillectomy and mesenteric lymph nodes obtained from patients undergoing abdominal surgery for various indications were dissected into $\sim 2$-mm blocks and incubated on top of collagen gels at the air-liquid interface. Culture medium was changed every $3 \mathrm{~d}$. Detailed culture methods have been described previously $(22,23)$.

Lymphoid histocultures were infected with the laboratory strains of HIV-1, LAV.04 and SF162, and with a primary HIV-1 isolate No. 302074 from an American infant (AIDS Research and Reagent Program, Division of AIDS, National Institute of Allergy and Infectious Diseases [NIAID], National Institutes of Health [NIH], Bethesda, $\mathrm{MD})$. To inoculate the lymphoid tissue histocultures, $1-5 \mu \mathrm{l}$ of clarified virus-containing medium (equivalent to 400-600 TCID ${ }_{50}$ ) was slowly applied on top of each tissue block. This dosage of HIV results in replication kinetics with a maximum within 12-14 d after infection $(22,23)$ which is the standard time frame for culturing the tissue blocks. Based on the average number of cells per block, this amount of virus corresponds to $\sim 0.001 \mathrm{TCID}_{50}$ per histoculture cell, a dosage less than that typically used for PBMC infection.

Two forms of MIP- $1 \alpha$ were used, and both gave similar results. The BB10010 variant of MIP-1 $\alpha$ was obtained from British Biotech, Oxford, United Kingdom (a generous gift of L. Czaplewski); recombinant wild type human MIP- $1 \alpha$, MIP- $1 \beta$, and RANTES were ob- 

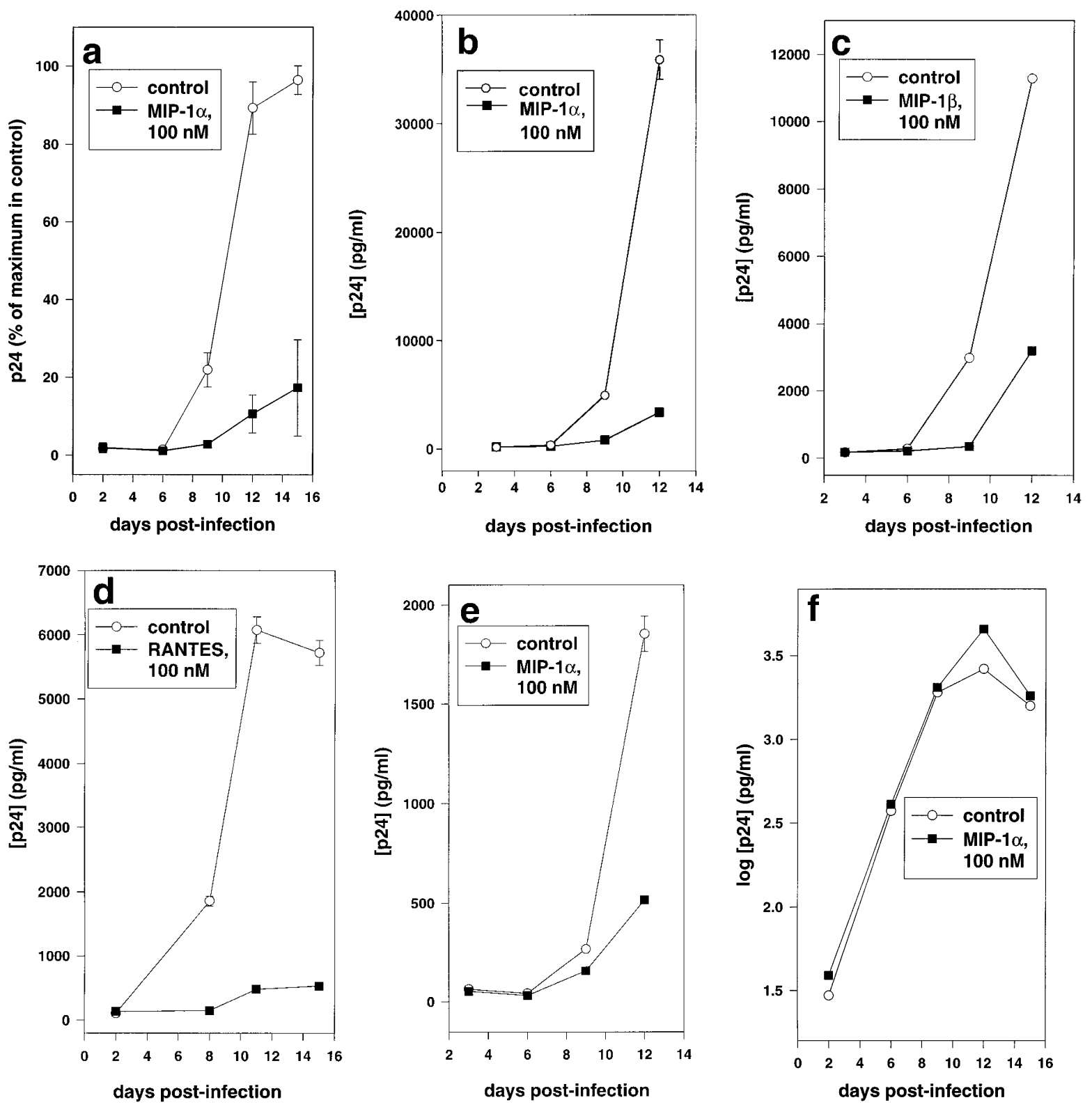

Figure 1. Chemokine inhibition of HIV-1 replication in human lymphoid tissue in vitro. Tissue blocks were infected with HIV-1 in the absence of added chemokines (circles) or after addition of $100 \mathrm{nM}$ MIP-1 $\alpha$, MIP-1 $\beta$, or RANTES (closed squares; as described in Methods), and were analyzed for p24 concentration in the culture medium at the times indicated. (a) Inhibition of SF162 (CCR5-tropic) infection in tonsil histoculture by MIP- $1 \alpha$ (mean \pm SEM of tissues from six different donors). (b) Inhibition of SF162 infection in lymph node histoculture by MIP-1 $\alpha$ (representative of experiments with tissues from two donors; mean \pm SEM of 12 pooled tissue blocks from an individual donor). (c) Inhibition of SF162 infection in lymph node histoculture by MIP-1 $\beta$ (mean of 12 pooled tissue blocks from an individual donor). (d) Inhibition of SF162 infection in tonsillar histoculture by RANTES (representative of experiments with tissues from two donors; mean \pm SEM of 12 pooled tissue blocks from an individual donor). (e) Inhibition of replication of primary isolate No. 302074 by MIP-1 $\alpha$ (each point is mean \pm SEM of 12 pooled tissue blocks from one donor; representative of two experiments). $(f)$ Lack of inhibition of LAV.04 (CXCR4-tropic) replication by MIP-1 $\alpha$ (mean of 12 tissue blocks from one donor. Representative of two experiments).

tained from PeproTech (Rocky Hill, NJ). Chemokines were added to the culture medium bathing the tissue blocks $3 \mathrm{~h}$ before infection, and then every $3 \mathrm{~d}$ with each medium change. The concentration of p24 and of CC chemokines in the medium was measured by ELISA (Cellular Products Inc., Buffalo, NY or NCI, Frederick, MD for p24 antigen, and R\&D Systems, Minneapolis, MN for CC chemokines).

\section{Results and Discussion}

Histocultures of human tonsils or mesenteric lymph nodes $\sim 2$ $\mathrm{mm}$ in diameter were cultured on top of collagen gel at the airliquid interface. Consistent with our previous reports $(22,23)$, the tissue supported productive infection with the CCR5- 
tropic strain SF162 and the nonsyncytium-inducing primary isolate No. 302074, as well as with the CCR5-independent strain LAV.04 which uses CXCR4 as a coreceptor (24). All three isolates replicated exponentially during the first $12 \mathrm{~d}$ of infection as evaluated by the amount of p24 in the bathing medium (Fig. 1).

Flow cytometry of cells mechanically isolated from tonsillar tissue showed that $\mathrm{CD}^{+}$and $\mathrm{CD}^{+} \mathrm{T}$ cells, $\mathrm{B}$ cells $\left(\mathrm{CD} 19^{+}\right)$, and macrophages $\left(\mathrm{CD}^{+} 8^{+} / \mathrm{HLA}-\mathrm{DR}^{+}\right)$were present in the tissue. This confirms our previously reported results obtained using immunohistochemical detection methodology (23). In the tissues from two donors, the number of macrophages was 25 and $33 \%$ of the number of $\mathrm{T}$ lymphocytes, respectively. On day 11 after infection, $1.9 \%$ of $\mathrm{T}$ cells and $0.2 \%$ of macrophages were $\mathrm{p} 24^{+}$for one donor, and $1.8 \%$ of $\mathrm{T}$ cells and $0.1 \%$ of macrophages were $\mathrm{p} 24^{+}$for the other. Although the contribution of each cell type to total HIV-1 replication in the tissue is unknown, it is clear that both cell types are productively infected in this system with productively infected lymphocytes $\sim 50$-fold more abundant than productively infected macrophages.
Replication of SF162 in tonsillar tissue was inhibited by MIP- $1 \alpha$ when it was added at $100 \mathrm{nM}$ before infection and replenished every $3 \mathrm{~d}$ thereafter with each media change (Fig. $1 \mathrm{a}$ ). At the maximum of SF162 replication, p24 production in the MIP- $1 \alpha$-treated histocultures was approximately eightfold lower than in infected untreated control lymphoid tissues from the same donor. Similar results were obtained in experiments on lymph node histocultures with MIP-1 $\alpha$ and MIP-1 $\beta$ (Fig. 1, $b$ and $c$ ). RANTES added at $100 \mathrm{nM}$ also inhibited SF162 replication in histocultures of human lymphoid tissue (Fig. 1d). The extent of inhibition observed for all three chemokines tested at $100 \mathrm{nM}$ was not significantly different. MIP- $1 \alpha$ at a concentration of $100 \mathrm{nM}$ also inhibited replication of the primary isolate No. 302074 in human tonsillar tissue (Fig. 1 e). The inhibition of HIV-1 replication was virus specific: MIP- $1 \alpha$ at $100 \mathrm{nM}$ failed to inhibit infection with the CXCR4-tropic strain LAV.04 (Fig. 1f).

It is important to note that a low level of virus replication persisted even when the tissue was continuously treated with $\mathrm{CC}$ chemokines (Fig. 1, $a-e$ ). Residual replication in the continuous presence of chemokines could reflect either incom-
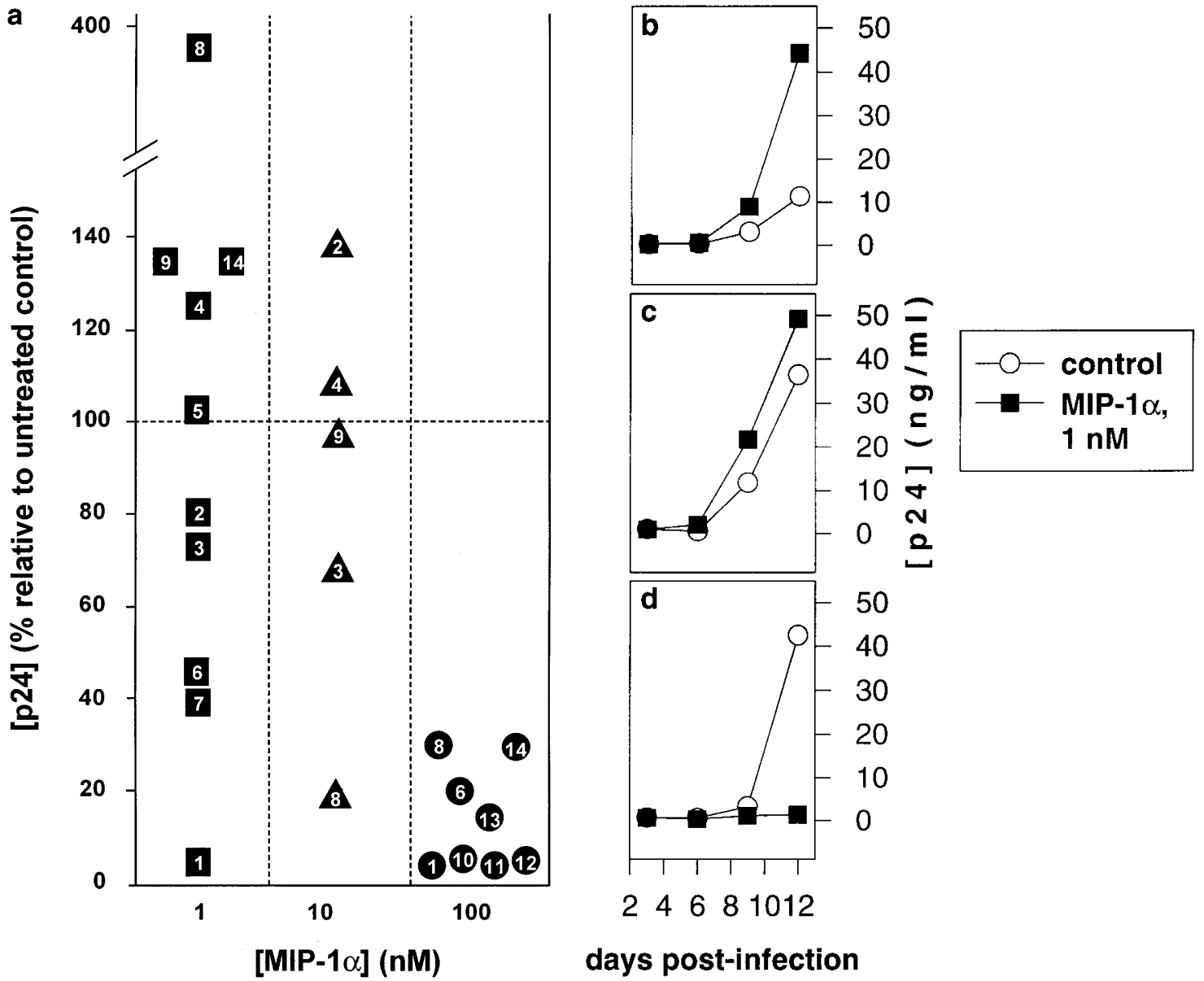

Figure 2. Concentration dependence of MIP-1 $\alpha$ modulation of CCR5-tropic HIV-1 replication in human lymphoid tissue in vitro. (a) Level of SF162 replication in tissue blocks from individual donors. Tissue blocks were continuously treated with the indicated concentration of MIP-1 $\alpha$. HIV-1 replication is expressed as percent of p24 level on days 10 to 12 after infection relative to infected but CC chemokine-untreated tissue blocks from the same donor. The donor No. is indicated on each symbol. Specimens No. 1-13 are tonsils, and specimen No. 14 is lymph node tissue. $(b-d)$ Representative time course for SF162 infection in lymphoid tissue in which replication was stimulated $(b)$, unaffected $(c)$, or inhibited (d) by $1 \mathrm{nM}$ MIP-1 $\alpha$, relative to the untreated infected control. 
plete blocking of CCR5 or the use of an alternative, albeit a less efficient, coreceptor. Residual low level replication was not due to increased capacity of the tissue to consume MIP- $1 \alpha$ during the course of the infection (data not shown). If MIP- $1 \alpha$ was not replenished at the day 3 media change, viral replication increased to $50 \%$ of control levels measured at day 12 after infection (data not shown). Thus, high levels of suppression require continuous presence of $\mathrm{CC}$ chemokines.

In contrast to the consistent ability of MIP- $1 \alpha$ to markedly suppress SF162 replication when tested at $100 \mathrm{nM}$, the magnitude of suppression by lower concentrations of MIP- $1 \alpha$ was highly variable among different donors. At one extreme, in tissues from 5 out of 10 donors, at least one of the low concentrations of MIP- $1 \alpha$ ( 1 or $10 \mathrm{nM})$ significantly stimulated viral replication relative to the control tonsillar tissue from the same donor (Fig. $2 a$ ). In other tissue blocks, either there was no effect on viral replication, or it was inhibited by these concentrations of MIP-1 $\alpha$ (Fig. $2 a$ ). The nature of the effect (inhibition versus stimulation versus no effect) was evident at the earliest time points when p24 in the medium became detectable, and then persisted throughout the culture period (Fig. 2, $b-d$ ). The absolute level of viral replication in tissue from different donors did not predict whether MIP- $1 \alpha$ would stimulate or inhibit viral replication, nor did it correlate with the magnitude of stimulation or inhibition.

The reason for donor-to-donor variability for HIV suppression with low doses of chemokines is unknown, but could include differences in expression of chemokine-directed proteases or in sequestration of chemokine, for example by binding to glycosaminoglycans, as well as differences in the ligand binding affinity for CCR5. The reported affinity has varied widely in different studies of the recombinant receptor, and is unknown for the native leukocyte receptor (13). Whatever the factors for donor-to-donor variability at low concentrations, clearly $100 \mathrm{nM}$ of the CC chemokines overcomes them. This concentration was also needed for maximally effective suppression of CCR5-tropic viral replication in PBMCs (5).

Since addition of as little as $1 \mathrm{nM}$ of exogenous MIP- $1 \alpha$ was able to affect viral replication in tissue from some donors, we evaluated whether endogenous CC chemokines reach a similar level. Although blocks of human tonsillar tissue cultured in vitro continued to secrete $\mathrm{CC}$ chemokines into the medium throughout the culture period, the level was much lower: the average concentration in 12 experiments with tissues from different donors over the 12-d culture period was $0.025 \pm 0.006$ $\mathrm{nM}$ for MIP- $1 \alpha$ and $0.040 \pm 0.016 \mathrm{nM}$ for MIP-1 $\beta$. However, the variation among different donors was high and for some donors reached $0.1-0.4 \mathrm{nM}$.

We next tested whether viral replication could modulate endogenous chemokine production in tonsillar tissue cultures. Previously it was shown that MIP- $1 \alpha$ and MIP-1 $\beta$ are induced in isolated human monocytes after infection with a CCR5tropic HIV-1 isolate (25). However, the CCR5-tropic isolate SF162 had no effect on endogenous levels of MIP-1 $\alpha$, MIP-1 $\beta$, or RANTES produced by lymphoid tissue (Fig. 3, $a$ and $b$ ). In contrast, CXCR4-tropic LAV.04 infection dramatically increased the amount of CC chemokines produced by lymphoid tissue starting from day 6 after infection (Fig. $3 a$ ). During days 10-12 after infection, tissue blocks infected with LAV.04 released $\sim 10$-fold more MIP-1 $\beta$ and sixfold more MIP- $1 \alpha$ compared to control (uninfected tissues from the same donor) (Fig. 3 b). RANTES secretion was much less affected (Fig. 3 $b)$. Thus, paradoxically, MIP- $1 \alpha$ and MIP- $1 \beta$ secretion in lymphoid tissue is upregulated by the CCR5-independent, CXCR4-tropic isolate LAV.04, but was not affected by the CCR5-tropic isolate SF162.

The maximal concentration of endogenous CC chemokine released to the media by tissue infected with CXCR4-tropic HIV-1 is at least 10-fold lower than the concentration of exogenous chemokine required to inhibit CCR5-tropic HIV-1 replication. However, the difference in the tissue may be much less. Conceivably, the concentration of endogenous CC chemokines in CXCR4-tropic virus-infected tissue could reach levels needed to modulate HIV-1 interaction with CCR5. If so, this would potentially provide a selective advantage for a CXCR4-tropic virus over a CCR5-tropic virus, and potentially

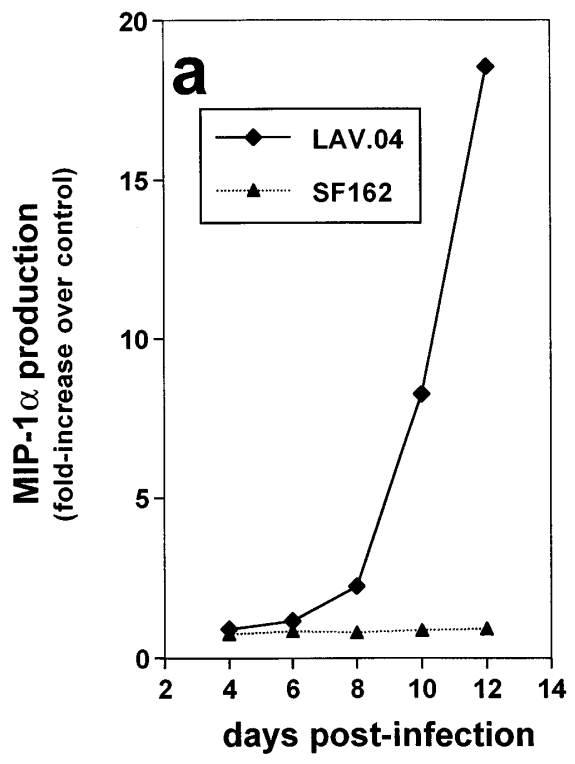

Figure 3. Differential modulation of endogenous CC chemokine production in human lymphoid histocultures infected with CCR5- and CXCR4-tropic HIV-1. Endogenous CC chemokines were assayed in culture medium from tonsillar tissue after infection ex vivo with the CXCR4-tropic strain LAV.04 or the CCR5-tropic strain SF162. (a) Time course for modulation of MIP- $1 \alpha$ production in human tonsillar histocultures by infection with LAV.04 or SF162 (representative of seven experiments). (b) Endogenous CC chemokine production in human tonsillar histocultures infected with SF162 or LAV.04. Data are from days 8 to 10 after infection (mean \pm SEM of experiments with tissue from five to nine different donors for each chemokine). The absolute values of $\mathrm{CC}$ chemokines for uninfected control tissues were $0.025 \pm 0.006 \mathrm{nM}$ for MIP- $1 \alpha$, $0.040 \pm 0.016 \mathrm{nM}$ for MIP-1 $\beta$, and $0.005 \pm 0.001 \mathrm{nM}$ for RANTES. 
explain the well-characterized viral phenotype switch from CCR5- to CXCR4-tropic virus that has been observed during the late stages of HIV pathogenesis (1-8). It is important to point out however that this switch does not occur in all patients (2), just as suppression of CCR5-tropic viral replication by low doses of exogenous $\mathrm{CC}$ chemokines did not occur in tissues from all individuals in our study. Whether this correlation has causal significance requires further study. In addition to directly regulating virus-coreceptor interactions, HIV-1-induced endogenous chemokines could act to chemoattract additional uninfected target cells ( $\mathrm{T}$ cells and monocytes) to sites of active viral replication (25).

In conclusion, our results demonstrate that the $\mathrm{CC}$ chemokines, MIP- $1 \alpha$, MIP-1 $\beta$, and RANTES can be used to inhibit replication of CCR5-tropic but not CXCR4-tropic HIV-1 in human lymphoid tissue, and are consistent with the notion that CCR5 is the major coreceptor used in vivo by CCR5tropic HIV-1 variants. Inhibition of viral infection required the continuous presence of high doses of CC chemokines, which were quite stable in the tissue. Unexpectedly, we found that low concentrations of CC chemokines stimulated viral replication in tissue from some donors. If stimulation depends on chemokine-induced signaling, then recently described pure antagonists of CCR5 may allow more consistent inhibition at low concentrations (26). The low level of residual viral replication in the presence of CC chemokines in our experiments suggests that, if they were to be used clinically, combination with other drugs would be necessary to completely inhibit viral infection in lymphoid tissue. In this regard, our system of cultured blocks of intact human lymphoid tissue may be useful for guiding the development of combinations of $\mathrm{CC}$ chemokines or $\mathrm{CC}$ chemokine-based drugs with other antivirals for clinical application.

\section{Acknowledgments}

We thank Dr. S. Hatfill for help in obtaining tissue samples; Dr. S. Yin for technical assistance; and Dr. J. Zimmerberg for advice and encouragement.

This work was supported, in part, by the NASA/NIH Center for Three-Dimensional Tissue Culture.

\section{References}

1. Fauci, A.S., G. Pantaleo, S. Stanley, and D. Weissman. 1996. Immunopathogenic mechanisms of HIV infection. Ann. Intern. Med. 124:654-663.

2. Tersmete, M., J.M. Lange, R.E. de Goede, F. de Wolf, J.K. EeftinkSchattenkerk, P.T. Schellekens, R.A. Coutinho, J.G. Huisman, J. Goudsmit, and F. Miedema. 1989. Association between biological properties of human immunodeficiency virus variants and risk for AIDS and AIDS mortality. Lancet. i: 983-985

3. Schuitemaker, H., M. Koot, N.A. Kootstra, M.W. Dercksen, R.E. de Goede, R.P. van Steenwijk, J.M. Lange, J.K. Schattenkerk, F. Miedema, and M. Tersmette. 1992. Biological phenotype of human immunodeficiency virus type 1 clones at different stages of infection: progression of disease is associated with a shift from monocytotropic to T-cell-tropic virus population. J. Virol. 66:13541360 .

4. Berger, E.A. 1997. HIV entry and tropism: the chemokine receptor connection. AIDS. 11:S3-S16.

5. Alkhatib, G., C. Combadiere, C.C. Broder, Y. Feng, P.E. Kennedy, P.M. Murphy, E.A. Berger. 1996. CC CKR5: a RANTES, MIP-1 $\alpha$, MIP-1 $\beta$ receptor as a fusion cofactor for macrophage-tropic HIV-1. Science. 272:1955-1958.

6. Choe, H., M. Farzan, Y. Sun, N. Sullivan, B. Rollins, P.D. Ponath, L. Wu,
C.R. Mackay, G. LaRosa, W. Newman, et al. 1996. The $\beta$-chemokine receptors CCR3 and CCR5 facilitate infection by primary HIV-1 isolates. Cell. 85:11351148 .

7. Deng, H., R. Liu, W. Ellmeier, S. Choe, D. Unutmaz, M. Burkhart, P. Di Marzio, S. Marmon, R.E. Sutton, C.M. Hill, C.B. Davis, et al. 1996. Identification of a major co-receptor for primary isolates of HIV-1. Nature. 381:661-666.

8. Dragic, T., V. Litwin, G.P. Allaway, S.R. Martin, Y. Huang, K.A. Nagashima, C. Cayanan, P.J. Maddon, R.A. Koup, J.P. Moore, and W.A. Paxton 1996. HIV-1 entry into CD4+ cells is mediated by the chemokine receptor CCCKR-5. Nature. 381:667-673.

9. Dean, M., M. Carrington, C. Winkler, G.A. Huttley, M.W. Smith, R. Allikmets, J.J. Goedert, S.P. Buchbinder, E. Vittinghoff, E. Gomperts, et al. 1996 Genetic restriction of HIV-1 infection and progression to AIDS by a deletion allele of the CKR5 structural gene. Hemophilia growth and development study, multicenter AIDS cohort study, multicenter hemophilia cohort study, San Francisco city cohort, ALIVE study. Science. 273:1856-1862.

10. Liu, R., W.A. Paxton, S. Choe, D. Ceradini, S.R. Martin, R. Horuk, M.E. MacDonald, H. Stuhlmann, R.A. Koup, and N.R. Landau. 1996. Homozygous defect in HIV-1 coreceptor accounts for resistance of some multiply-exposed individuals to HIV-1 infection. Cell. 86:367-377.

11. Samson, M., O. Labbe, C. Mollereau, G. Vassart, and M. Parmentier. 1996. Resistance to HIV-1 infection in Caucasian individuals bearing mutant alleles of the CCR-5 chemokine receptor gene. Nature. 382:722-725.

12. Zimmerman, P.A., A. Buckler-White, G. Alkhatib, T. Spalding, J. Kubofcik, C. Combadiere, D. Weissman, O. Cohen, A. Rubbert, G. Lam, et al. 1997. Inherited resistance to HIV-1 conferred by an inactivating mutation in CC chemokine receptor 5: studies in populations with contrasting clinical phenotypes, defined racial background, and quantified risk. Mol. Med. 3:23-36.

13. Combadiere, C., S.K. Ahuja, H.L. Tiffany, and P.M. Murphy. 1996. Cloning and functional expression of CC CKR5, a human monocyte CC chemokine receptor selective for MIP-1 $\alpha$, MIP-1 $\beta$, and RANTES. J. Leukocyte Biol. 60:147-152.

14. Raport, C.J., J. Gosling, V.L. Schweickart, P.W. Gray, and I.F. Charo 1996. Molecular cloning and functional characterization of a novel human CC chemokine receptor (CCR5) for RANTES, MIP-1 $\beta$, and MIP-1 $\alpha . J$. Biol. Chem. 271:17161-17166.

15. Samson, M., O. Labbe, C. Mollereau, G. Vassart, and M. Parmentier. 1996. Molecular cloning and functional expression of a new human CCchemokine receptor gene. Biochemistry. 35:3362-3367.

16. Cocchi, F. A.L. DeVico, A. Garzino-Demo, S.K. Arya, R.C. Gallo, and P. Lusso. 1995. Identification of RANTES, MIP-1 $\alpha$, and MIP-1 $\beta$ as the major HIV-suppressive factors produced by CD8+ T cells. Science. 270:1811-1815.

17. Wu, L., K.J. Munroe, B.H. Gardner, M.S. Wyand, and M.J. Newman. 1996. CD4-induced interaction of primary HIV-1 gp120 glycoproteins with the chemokine receptor CCR-5. Nature. 384:179-183.

18. Schmidtmayerova, H., B. Sherry, and M. Bukrinsky. 1996. Chemokines and HIV replication. Nature. 382:767.

19. Fox, C.H., K. Tenner-Racz, P. Racz, A. Firpo, P.A. Pizzo, and A.S Fauci. 1991. Lymphoid germinal centers are reservoirs of human immunodeficiency virus type 1 RNA. J. Infect. Dis. 164:1051-1057.

20. Pantaleo, G., C. Graziosi, J.F. Demarest, O.J. Cohen, M. Vaccarezza, K. Gantt, C. Muro-Cacho, and A.S. Fauci. 1994. Role of lymphoid organs in the pathogenesis of human immunodeficiency virus (HIV) infection. Immunol. Rev. 140:105-130.

21. Frankel, S.S., B.M. Wenig, A.B. Burke, P. Mannan, L.D.R. Thompson, S. Abbondanzo, A.M. Nelson, M. Pope, and R.M. Steinman. 1996. Replication of HIV-1 in dendritic cell-derived syncytia at the mucosal surface of the adenoids. Science. 272:115-117.

22. Glushakova, S., B. Baibakov, L.B. Margolis, and J. Zimmerberg. 1995. Infection of human tonsil histocultures: a model for HIV pathogenesis. Nat. Med. 1:1320-1322.

23. Glushakova, S., B. Baibakov, J. Zimmerberg, and L. Margolis. 1997. Experimental HIV infection of human lymphoid tissue: Correlation of CD4+ T cell depletion and virus syncytium-inducing/non-syncytium-inducing phenotype in histoculture inoculated with laboratory strains and patient isolates of HIV-1. AIDS Res. Hum. Retroviruses. 13:461-471.

24. Feng, Y., C.C. Broder, P.E. Kennedy, and E.A. Berger. 1996. HIV-1 entry cofactor: functional cDNA cloning of a seven-transmembrane, $\mathrm{G}$ proteincoupled receptor. Science. 272:872-877.

25. Schmidtmayerova, H., H.S. Nottet, G. Nuovo, T. Raabe, C.R. Flanagan, L. Dubrovsky, H.E. Gendelman, A. Cerami, M. Bukrinsky, and B. Sherry. 1996. Human immunodeficiency virus type 1 infection alters chemokine $\beta$ peptide expression in human monocytes: implications for recruitment of leukocytes into brain and lymph nodes. Proc. Natl. Acad. Sci. USA. 93:700-704.

26. Simmons, G., P.R. Clapham, L. Picard, R.E. Offord, M.M. Rosenkilde, T.W. Schwartz, R. Buser, T.N.C. Wells, and A.E. Proudfoot. 1997. Potent inhibition of HIV-1 infectivity in macrophages and lymphocytes by a novel CCR5 antagonist. Science. 276:276-279. 